University of South Carolina

Scholar Commons

$8-2010$

\title{
Wind Speed Dependence of Single-Site Wave-Height Retrievals from High-Frequency Radars
}

\author{
Brian K. Haus \\ University of Miami \\ Lynn K. Shay \\ University of Miami \\ Paul A. Work \\ Georgia Institute of Technology - Main Campus \\ George Voulgaris \\ University of South Carolina - Columbia, gvoulgaris@geol.sc.edu \\ Rafael J. Ramos \\ University of Miami
}

See next page for additional authors

Follow this and additional works at: https://scholarcommons.sc.edu/geol_facpub

Part of the Earth Sciences Commons

\section{Publication Info}

Published in Journal of Atmospheric and Oceanic Technology, Volume 27, 2010, pages 1381-1394.

Haus, B. K., Shay, L. K., Work, P. A., Voulgaris, G., Ramos, R. J., \& Martinez-Pedraja, J. (2010). Wind speed dependence of single-site wave-height retrievals from high-frequency radars. Journal of Atmospheric and Oceanic Technology, 27, 1381-1394.

(c) Copyright 2010 AMS

This Article is brought to you by the Earth, Ocean and Environment, School of the at Scholar Commons. It has been accepted for inclusion in Faculty Publications by an authorized administrator of Scholar Commons. For more information, please contact digres@mailbox.sc.edu. 


\section{Author(s)}

Brian K. Haus, Lynn K. Shay, Paul A. Work, George Voulgaris, Rafael J. Ramos, and Jorge Martinez-Pedraja 


\title{
Wind Speed Dependence of Single-Site Wave-Height Retrievals from High-Frequency Radars
}

\author{
Brian K. Haus, ${ }^{*}$ Lynn K. Shay, ${ }^{+}$PAul A. Work, ${ }^{\#}$ George Voulgaris, ${ }^{@}$ \\ RAFAEL J. RAMOS,* AND JORGE MARTINEZ-PEDRAJA ${ }^{+}$ \\ * Division of Applied Marine Physics, Rosenstiel School of Marine and Atmospheric Science, \\ University of Miami, Miami, Florida \\ ${ }^{+}$Division of Meteorology and Physical Oceanography, Rosenstiel School of Marine \\ and Atmospheric Science, University of Miami, Miami, Florida \\ \# School of Civil and Environmental Engineering, Georgia Institute of Technology, Savannah, Georgia \\ @ Department of Earth and Ocean Sciences, Marine Science Program, University of South Carolina, \\ Columbia, South Carolina
}

(Manuscript received 20 July 2009, in final form 11 March 2010)

\begin{abstract}
Wave-height observations derived from single-site high-frequency (HF) radar backscattered Doppler spectra are generally recognized to be less accurate than overlapping radar techniques but can provide significantly larger sampling regions. The larger available wave-sampling region may have important implications for observing system design. Comparison of HF radar-derived wave heights with acoustic Doppler profiler and buoy data revealed that the scale separation between the Bragg scattering waves and the peak energy-containing waves may contribute to errors in the single-site estimates in light-to-moderate winds. A wave-height correction factor was developed that explicitly considers this scale separation and eliminates the trend of increasing errors with increasing wind speed.
\end{abstract}

\section{Introduction}

High-frequency (HF) radars have been widely implemented as a key component of the Integrated Ocean Observing System (IOOS) in the United States and around the world. Typically the radars' primary purpose in the observing system is to map ocean surface currents. However, there is significant interest in exploiting their capability for wave observing to provide important coastal information that may be otherwise quite limited (Voulgaris et al. 2008). Single-site waveheight retrieval methods offer the advantage of expanded coverage regions and are more appropriate for the widely spaced sites typical of observing systems designed for surface current mapping.

\section{a. HF radar wave observations}

In addition to the first-order Bragg resonances first observed by Crombie (1955), the echo Doppler spectrum

Corresponding author address: Brian K. Haus, RSMAS/AMP, University of Miami, 4600 Rickenbacker Causeway, Miami, FL 33149. E-mail: bhaus@rsmas.miami.edu derived from a typical HF radar contains significant energy at adjacent frequency bands (Fig. 1). These secondorder returns contain backscattered energy resulting from multiple reflections of the radar signal as well as from the hydrodynamic interaction between surface waves to produce a Bragg scattering wave (Hasselmann 1971).

Barrick (1972) derived expressions that relate the first- and second-order returns to the ocean surface wave energy spectra. Methods to invert the Barrick (1972) equations and retrieve the surface wave directional energy spectrum have been developed by Lipa (1978), Lipa and Barrick (1986), Wyatt (1990), Howell and Walsh (1993) and Hisaki (1996). Wyatt et al. (1999) demonstrated that when using two radar sites, inversion methods can yield reliable wave directional spectral estimates comparable to those recorded by moored buoys. These methods require that the second-order returns are sufficiently above the noise floor to be measured by two overlapping radar stations. This restricts the available sampling region much more than for surface current observations (Wyatt et al. 2005) because the second-order returns have lower signal-to-noise ratios (SNRs) than 
(a)

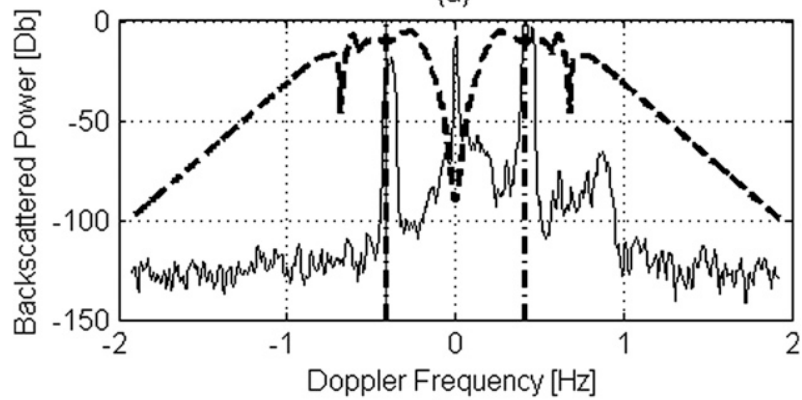

(b)

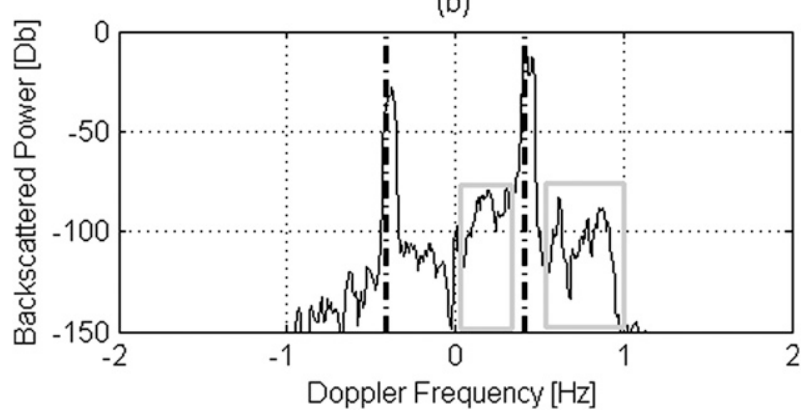

FIG. 1. (a) Example echo Doppler spectrum (solid line), chosen because of nearly ideal peak separation and low noise floor, as observed by WERA deployed in southeast Florida. Decibel scale normalized by peak of backscattered spectrum. Bragg peaks for $16.045 \mathrm{MHz}(-\mathbf{-})$ and weighting function as derived by Barrick $(1977 b$; $\mathbf{a})$ are shown. (b) Spectrum normalized by weighting function. Second-order regions used for wave heights (gray boxes) are shown.

first-order returns. In many cases HF radars are positioned to optimize surface current coverage at the expense of a limited region of appropriate overlap for dual-site wave retrievals (Voulgaris et al. 2008; Wyatt et al. 2009).

Alternatively, single-site Doppler spectra can be processed on site to obtain and transmit scalar wave height and period information (Heron et al. 1985). Barrick (1977a) derived an expression to estimate rootmean-square wave height $\left(\hat{H}_{\mathrm{rms}}\right)$ using the ratio between the second- and first-order returns, as

$$
\hat{H}_{\mathrm{rms}}^{2}=\frac{2 \int_{-\infty}^{\infty}\left[\sigma_{2}\left(\omega_{d}\right) W\left(f_{d}\right) d f_{d}\right]}{k_{0}^{2} \int_{-\infty}^{\infty} \sigma_{1}\left(f_{d}\right) d f_{d}},
$$

where $\sigma_{1}$ and $\sigma_{2}$ are the first- and second-order backscattered energy at each Doppler frequency $\left(f_{d}\right)$ and $k_{0}$ is the radar wavenumber. The weighting function $W\left(f_{d}\right)$ is used to suppress energy received at zero Doppler shift, energy far removed from the Bragg peaks, and energy in regions of the Doppler frequency space that are particularly sensitive to direction (Barrick 1977b).

It has been shown by Wyatt (2002) that single-site wave-height retrievals can have larger errors when the surface waves are propagating at large angles to the radar-look direction, defined as the angle between the radar boresight and the radial line from the receiver to the observation cell of interest. To improve the wave retrievals if the radar-look direction is known with sufficient accuracy, Barrick (1977a) recommended that a correction factor $\left(\varepsilon_{H}\right)$ be applied to the wave-height estimate,

$$
H_{\mathrm{rms}}=\varepsilon_{H} \hat{H}_{\mathrm{rms}},
$$

where $\hat{H}_{\text {rms }}$ is the wave-height estimate computed from (1). Barrick (1977a) suggested that a correction factor with mean of 0.8 and a standard deviation of 0.2 was sufficient to encompass most of the variability. Heron and Heron (1998) found that a scaled correction factor provided the best fit of wave height to wave buoy data over a limited wave-height range.

This empirical approach was implemented for the phased array Ocean Surface Current Radar (OSCR) HF radars by Graber and Heron (1997). It was extensively tested by Ramos et al. (2009), where rms differences in the significant wave height $\left(H_{s}\right)$ between 0.21 and $0.70 \mathrm{~m}$ were found in comparisons with multiple sets of in situ observations. These observed differences are of the same order as those typically found between in situ observations (Graber et al. 2000). Larger differences between radar-observed and in situ $H_{s}$ observations occurred at long ranges from the radar stations (Ramos et al. 2009), in regions of high spatial variability of the wave field (Haus et al. 2006), and at large angles from the radar boresight (i.e., direction of line perpendicular to the receiver antenna array) (Voulgaris et al. 2008).

\section{b. Surface wave directional spreading functions}

The Barrick (1977a) equations on which this study is based were derived using assumptions that allowed for integrating out directionality. However, these assumptions may be more restrictive during particular surface wave and/or radar sampling conditions. To better understand the range of applicability of these fundamental assumptions and to determine the appropriate correction factor, the directional spreading of the surface waves at both the peak wavenumber and at the Bragg wavenumber will be investigated. This is necessary because both the first-order $\left(\sigma_{1}\right)$ and second-order $\left(\sigma_{2}\right)$ backscattered radar energy appear in (1). Other investigators (Long and Trizna 1973; Heron and Rose 1986; de Valk et al. 1999; Hisaki 2005) suggest a $\cos ^{2 s}(\theta)$ spreading of the wave energy about the mean wave direction based on a model suggested by Longuet-Higgins et al. (1963), 


$$
\begin{aligned}
& \Psi(k, \theta)=\frac{1}{k} S(k) \Phi(k, \theta), \\
& \Phi(k, \theta)=G(s) \cos \left(\frac{\theta^{*}}{2}\right)^{2 s},
\end{aligned}
$$

where, $S(k)$ is the one-dimensional energy distribution over wavenumber $(k), \Phi$ is the directional distribution defined for all $k$ and directions $(\theta), \theta^{*}=\theta-\theta_{W}$ is the angle between the direction of interest and the mean wave direction $\left(\theta_{W}\right)$, and $s$ is an empirically defined spreading parameter. A significant shortcoming of this form of spreading function for HF radar applications is that it does not include any waves traveling directly against the wind direction. This contrasts with observed HF Doppler spectra, which almost always include both positively and negatively Doppler-shifted signals in the first-order returns.

More recent work by Wyatt (2002) and Gürgel et al. (2006) have suggested that a spreading function based on hyperbolic secants (Donelan et al. 1985) is more appropriate for $\mathrm{HF}$ radar inversions because it allows wave energy to propagate orthogonally to the mean direction:

$$
\begin{aligned}
\Phi(k, \theta) & =\operatorname{sech}^{2}\left(\beta \theta^{*}\right), \\
\beta & =2.61\left(\frac{\omega}{\omega_{p}}\right)^{1.3}, \quad \text { for } 0.56<\omega / \omega_{p}<0.95, \\
\beta & =2.28\left(\frac{\omega}{0.95 \omega_{p}}\right)^{-1.3}, \text { for } 0.95<\omega / \omega_{p}<1.6, \\
\beta & =1.24 \text { otherwise; }
\end{aligned}
$$

where $\omega$ is the surface wave frequency $\left(\operatorname{rad~s}^{-1}\right)$ and the subscript $p$ denotes the value at the spectral peak. Wyatt et al. (1997) used a maximum likelihood estimation technique to determine $\beta$ and $\theta^{*}$ from $\mathrm{HF}$ radar data for ocean waves at the Bragg scattering frequency. Banner (1990) extended the wavenumber range of this spreading function and presented the directional distribution for both advancing and receding waves.

Apel (1994) derived an expression for the directional spreading function (ASF), which is an approximation of the Donelan et al. (1985) and Banner (1990) functions based on a Gaussian distribution instead of the hyperbolic secant function,

$$
\begin{aligned}
\Phi(k, \theta) & =\exp \left[\frac{-\left(\theta^{*}\right)^{2}}{2 \phi_{s}^{2}(k)}\right], \\
2 \varphi_{s}^{2} & =\left[0.14+5.0\left(\frac{k}{k_{p}}\right)^{-1.3}\right]^{-1} .
\end{aligned}
$$

The advantages of the ASF (5) are that it is easier to invert, it is a continuous function over all wavenumbers, and it allows for opposing waves.

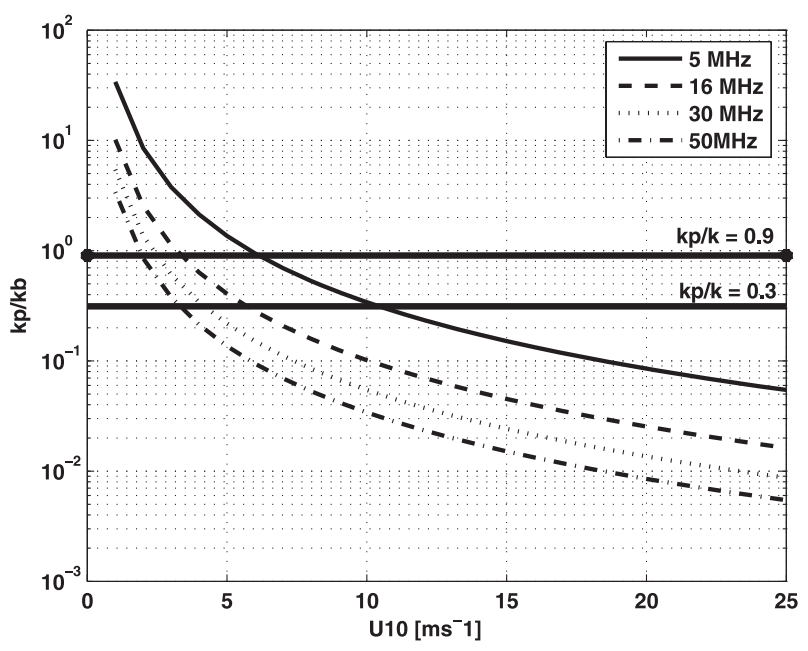

FIG. 2. Wind speed dependence of the ratio of the Bragg scattering wavenumber at various $\mathrm{HF}$ and VHF frequencies to the wavenumber of the spectral peak as calculated from Donelan and Pierson (1987). Wavenumbers of inflection points $\left(k_{p} / k=0.3,0.9\right)$ in the Donelan et al. (1985) directional spreading function are shown.

\section{c. Wind speed effects}

The dependence of directional spreading on wind speed has long been known from field observations. It is incorporated in the spreading parameter $s$ (Mitsuyasu et al. 1975) in (3) and through the ratios $\omega / \omega_{p}$ and $k / k_{p}$ in (4) and (5), respectively (Hasselmann et al. 1980; Donelan et al. 1985). The peak wavenumber of the fully developed omnidirectional spectrum is related to the inverse of the squared wind speed (Donelan and Pierson 1987) through

$$
k_{p}=\left(\frac{g}{1.2 U_{10 N}}\right)^{2}
$$

where $g$ is the gravitational acceleration and $U_{10 N}$ is the neutrally stable wind speed $10 \mathrm{~m}$ above the mean sea surface.

The wind speed dependence of the directional spreading presents a problem when inverting HF radar signals (frequencies of $5-30 \mathrm{MHz}$ ) because the $\mathrm{HF}$ Bragg scattering wavenumbers $\left(k_{B}=\omega_{B}^{2} / g\right)$ in deep water are in the range where $k_{p} / k_{B}$ varies significantly (Fig. 2). This is in contrast to microwaves for which $k_{B}$ is much larger and $k_{p} / k_{B}$ is small for all except the lightest winds. This wind speed dependence is evident at all HF frequencies (Fig. 2), but it has not been previously explored.

In this manuscript we examine the interdependencies between wind speed and directional wave spectra in order to improve the estimates of wave height from $\mathrm{HF}$ radars. In particular, we evaluate the effect of the wind 
(a)

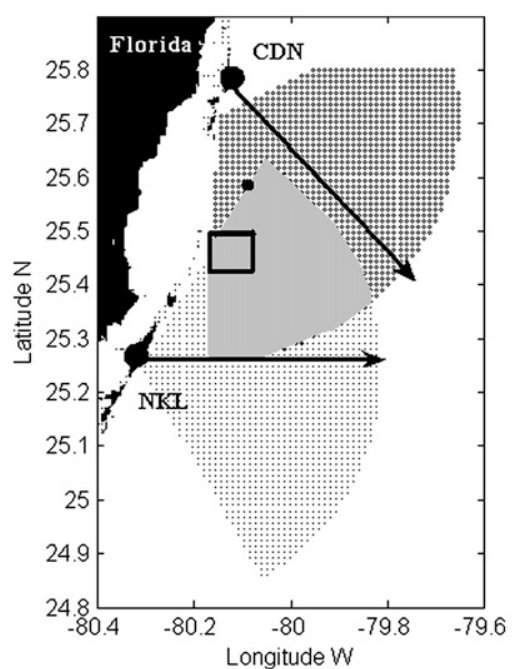

(b)

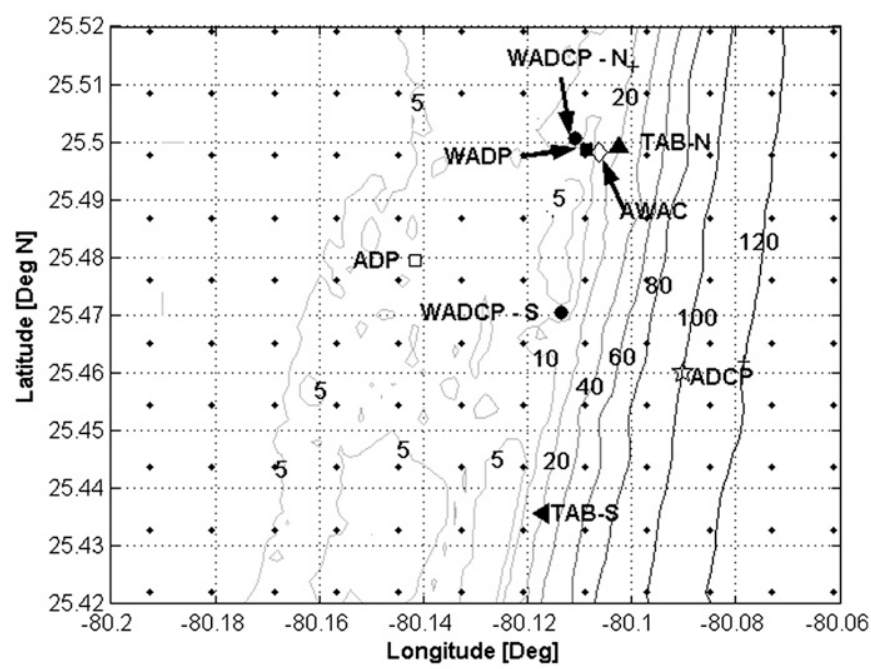

FIG. 3. (a) Wave coverage area of WERA as deployed for SEACOOS based on a 50-km-range limitation and a $120^{\circ}$ angular swath from the NKL station and $90^{\circ}$ from the CDN. The direction of the normal to the receive array (boresight) of each radar station are shown (solid arrows). The area where the two stations overlap is denoted (shaded region). The location of the Fowey Rocks CMAN station is shown (solid circle). (b) The region is expanded (box). In situ measurement locations: WADP: 1500-kHz Sontek ADP with waves package, WADCP: 1200-kHz RDI waves ADCP, AWAC: Nortek current meter, and TAB-N,S: TriAxys directional wave buoys. Depth contours are shown $(\mathrm{m})$.

speed on surface wave directional spreading for the purpose of improving single-site wave-height retrievals. A new correction factor is defined in section 2 based on the Apel (1994) directional distribution of both the peak waves and the Bragg scattering waves. Calibration and validation of the wave-height measurements with in situ observations as well as the effects of the correction factor are presented in section 3. A discussion of the sensitivity of the wave-height retrievals to wind speed and direction follows in section 4 .

\section{Methods}

This study will use in situ wave observations from acoustic profilers and buoys deployed in the spring of 2005 in the Florida Straits to calibrate and validate HF radar-derived wave-height observations.

\section{a. HF radar measurements}

The HF radars used for these studies were a pair of Wellen radars (WERA; Gurgel et al. 1999) deployed as a component of the Southeast Atlantic Coastal Ocean Observing System (SEACOOS) as described by Shay et al. (2007) and Voulgaris et al. (2008). The WERA system uses frequency-modulated continuous wave (FMCW) transmission and a linear phased-array receiver. WERA, as deployed in SEACOOS, consists of two transmit-receive stations. The northern station is located in a Miami-Dade County park, Crandon Park $(\mathrm{CDN})$; the southern station is located in Florida's North Key Largo Hammocks Biological Preserve (NKL; see Fig. 3). Each station operates with a linear 16-element phased-array receiver and a rectangular 4-element transmitter. Basic operating parameters are listed in Table 1.

Limited accessible coastline in the area required $50-\mathrm{km}$ spacing between the two radar stations (Fig. 3a). This provided a large area for current mapping, with the region of consistent current vector retrievals extending well out over the Florida Straits (Parks et al. 2009). The large distance between stations limited the region for which directional spectra could be measured using twosite methods to a relatively small area (Wyatt et al. 2005). However, because the empirical method used here does not require overlap between the two stations, a larger area was available over which wave parameters could be computed (Haus 2007).

The echo Doppler spectra have been archived at each radar station for the period from June 2004 until June 2010. For these measurements the WERA actively transmitted and received for 5 min (1024 samples) successively from each site, with the measurement cycle repeated every $20 \mathrm{~min}$. The number of retrieved spectra varies with SNRs but, on average, from each record 1500 independent echo Doppler spectra were computed. The 
TABLE 1. WERA system characteristics as deployed over the southeast Florida shelf during this study.

\begin{tabular}{ll}
\hline \hline University of Miami WERA system \\
\hline Operating frequency & $16.045 \mathrm{MHz}$ \\
Peak transmitted power & $30 \mathrm{~W}$ \\
Bragg wavelength & $9.35 \mathrm{~m}$ \\
Nominal measurement depth & $0.8 \mathrm{~m}$ \\
Operating range & $80-120 \mathrm{~km}$ \\
Range resolution & $1.2 \mathrm{~km}$ \\
Integration time & $5 \mathrm{~min}$ \\
Azimuthal resolution (3-dB down) & $2^{\circ}$ \\
Accuracy of radial current component & $0.02 \mathrm{~m} \mathrm{~s}^{-1}$ \\
\hline
\end{tabular}

archived Doppler spectra were then postprocessed to derive wave heights $\left(H_{\mathrm{rms}}\right)$ as described below.

\section{b. Initial wave-height estimates}

The empirical method of Ramos et al. (2009), which is based on (1), was implemented to compute wave heights from the spectra derived from the WERA system. The integration in (1) was limited to the half of the spectrum that contained the most energy in the first-order peak, either $0 \leq f_{d} \leq f_{B}$ or $f_{B} \leq f_{d} \leq \infty$. In practice, narrower bounds were used that begin from the null of the firstorder Bragg peaks (Fig. 1b).

Ramos et al. (2009) studied the consistency of the coefficient $\alpha$ in (1) and found that, on average, it was quite robust and did not require adjustment to yield wave parameters that fit observed OSCR data collected during three independent experiments. The value of $\alpha$ determined by Ramos et al. (2009) was used as an initial guess in the present study, even though it could differ because of radar data quality or wave characteristics. The wave-height estimates from each WERA cell were then compared with a limited (25 day) series of in situ wave-height observations (calibration series, see section $2 c$ ) and a new $\alpha$ value was derived. The modified coefficient $\alpha$ was then used to produce revised wave-height estimates, which were then validated against a 45-day series of in situ wave-height observations that did not overlap with the calibration series.

\section{c. Correction factor}

To determine the effect of the wind speed on the correction factor we need to consider the disparate spreading about the peak waves and the Bragg waves. If the frequency spectrum is unimodal (i.e., no swell), then the main contribution to the surface wave height is distributed about the spectral peak as defined by (6). Using the ASF, the directional distribution about the peak does not exhibit any wind speed dependence because $k_{p}$ is already adjusted for the wind speed.
Conversely, at the HF radar frequency used for the experimental validation $\left(16 \mathrm{MHz}, k_{B}=0.67 \mathrm{~m}^{-1}\right)$, the Bragg wave energy varies significantly with both wind speed and relative direction to the wind (Fig. 4a). At other HF radar frequencies the distribution of is qualitatively similar with somewhat less (or more) wind speed dependence at lower (or higher) frequencies.

Because of the differing wind speed and wave angle dependence of the Bragg waves, as compared with the peak energy-containing waves (Fig. 4a), the correction factor $\left[\varepsilon_{H}\right.$ in Eq. (2)] should be proportional to the ratio of surface wave energy at these wavenumbers. It can be estimated using (5) and the angle between the radarlook direction and the local wind direction $\left(\theta^{r w}\right)$ by assuming the waves are centered about the wind direction $\left(\theta^{*}=\theta^{r w}\right)$ as

$$
\varepsilon_{H}=\frac{\Delta_{\theta}\left(k_{B}\right)}{\int_{k_{L}}^{k_{U}} \Delta_{\theta}(k) \frac{d k}{k}},
$$

where the lower and upper wavenumber limits $\left(k_{L}\right.$ and $k_{U}$, respectively) are chosen to encompass most of the ocean surface wave energy. The magnitude of the correction factor is quite sensitive to these limits. For example, if $k_{L}=k_{p} / 2$ and $k_{U}=2 k_{p}$, then $\varepsilon_{H}$ reaches a maximum value of 4 at off-wind angles approaching $90^{\circ}$ (Fig. 4c). If both limits are set more broadly about the peak wavenumber $\left(k_{L}=k_{p} / 4, k_{U}=4 k_{p}\right)$, then the pattern of the correction factor is similar but reaches a maximum value of only 1.2 (Fig. $4 \mathrm{~d})$. The narrower limits $\left(k_{L}=k_{p} / 2\right.$ and $k_{U}=2 k_{p}$ ) were chosen for this study based on the requirement that there be no overlap between the waves in the peak range and in the Bragg range. For winds above $4 \mathrm{~m} \mathrm{~s}^{-1}$, this requires that the upper limit is set at $2 k_{p}$ for the 16-MHz Bragg of interest, as seen in Fig. 1. The lack of significant swell waves in the study region (e.g., Fig. 4b) suggests that a narrower bound $\left(k_{p} / 2\right)$ on the lower wavenumber limit is appropriate in this case.

\section{d. In situ measurements}

Two Triaxys wave buoys and three wave-measuring acoustic current profilers were deployed within the WERA measurement domain on the southeast Florida shelf from March to May 2005 (Fig. 3b). Hourly wave observations were recorded by the in situ sensors based on 20-min burst sampling at the beginning of each hour. In addition, a bottom-mounted Sontek acoustic Doppler profile (ADP) with the ability to measure waves was deployed. The Sontek-derived wave estimates were used for calibration during the period of yearday (YD) 75-100, and the Triaxys buoys were used for validation for the period of YD 100-145, as discussed in the results section. Details of the sensor configuration and measurement 
(a)

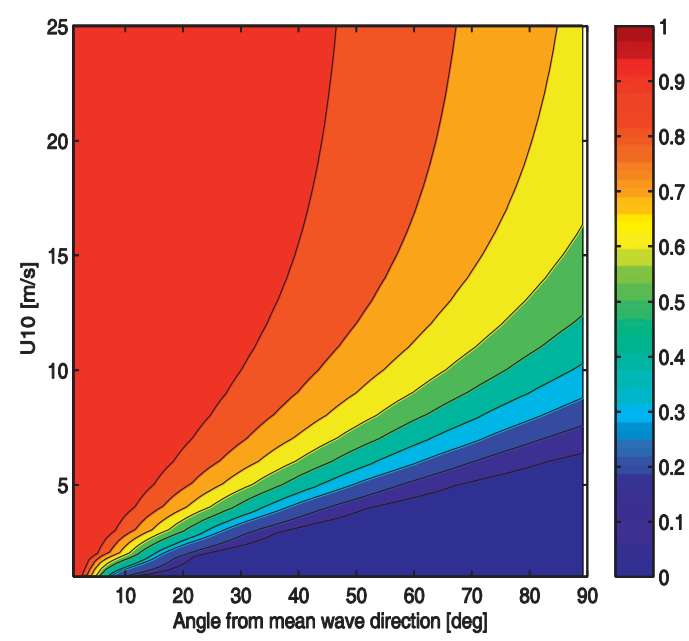

(c)

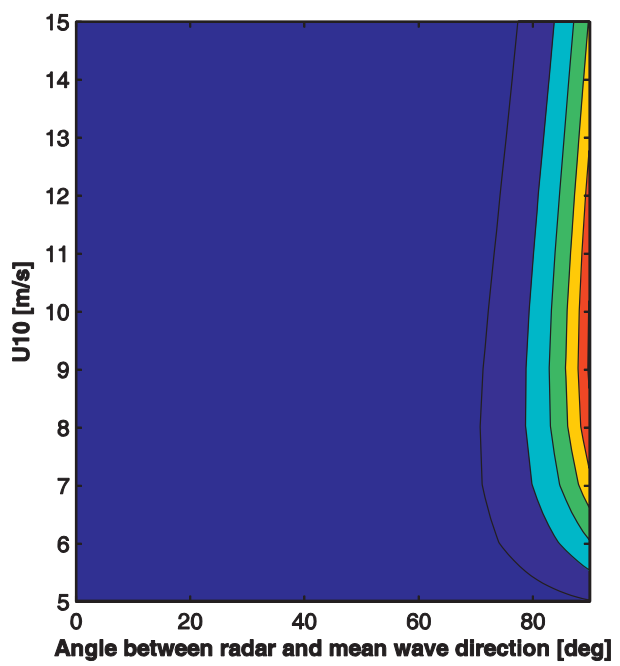

(b)

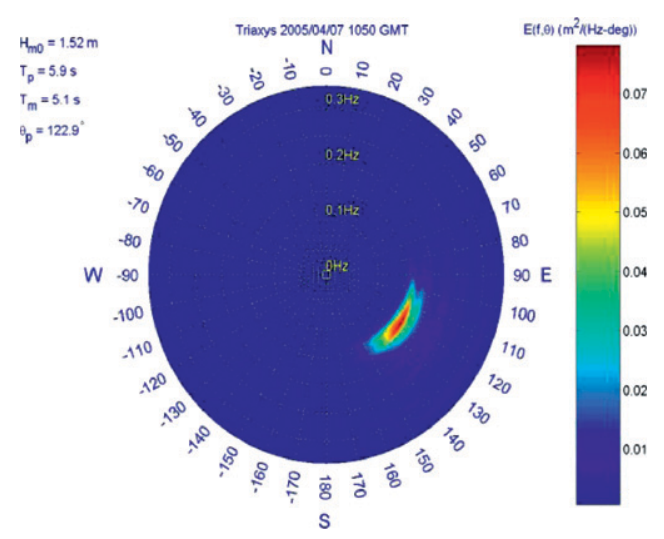

(d)

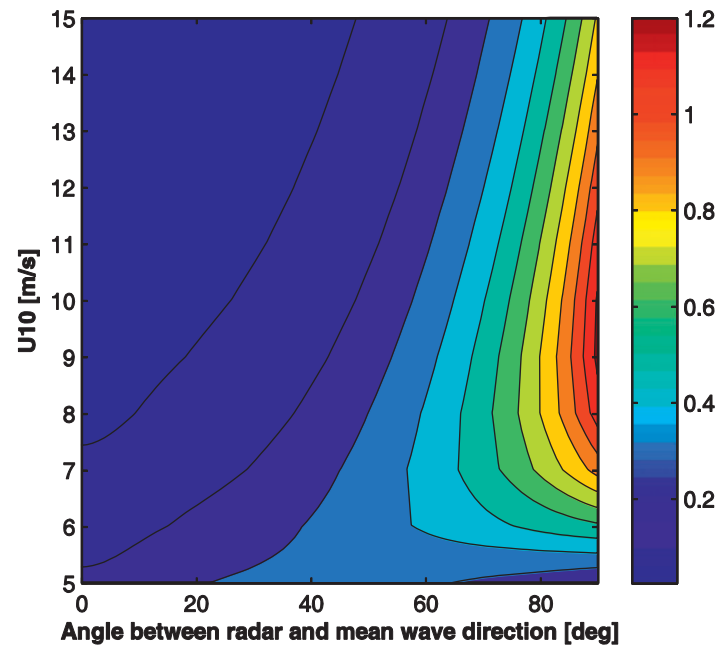

FIG. 4. (a) Apel (1994) spreading function for Bragg waves corresponding to $16-\mathrm{MHz} \mathrm{HF}$ radar $\left(k_{B}=0.67 \mathrm{~m}^{-1}\right) \mathrm{vs}$ angle between the radar and the mean wave direction. Peak wavenumber $\left(k_{p}\right)$ given by Donelan and Pierson (1987); the wind speed at $10-\mathrm{m}$ height as determined by a log-profile with a stability correction. (b) Hourly wind-wave frequency direction spectrum recorded at TAB-N at 1050 UTC YD 97. (c) Correction factor based on ASF as shown in (a), lower limit: $k_{p} / 2$ and upper limit: $2 k_{p}$. (d) As in (c), but the correction factor is based on ASF as shown in (a); lower limit: $k_{p} / 4$ and upper limit: $4 k_{p}$.

characteristics can be found in Work (2008) and Voulgaris et al. (2008).

All of the in situ sensors report directional wave energy spectra, from which nondirectional spectra and bulk parameters defining wave height, period, and direction were computed. The measured wave height in each case is defined as

$$
\begin{aligned}
H_{m 0} & =4.0 \sqrt{m_{0}}, \\
m_{0} & =\int_{f_{\text {low }}}^{f_{\text {high }}} E(f) d f,
\end{aligned}
$$

where $m_{0}$ is the total energy within the wave spectrum between the upper and lower cutoff frequencies (9). This value will be assumed to equal the significant wave height for both the buoys and radar observations hereafter.

\section{Results}

The wave-height data from the WERA system had not been previously calibrated for the empirical derivation of wave heights using (1). Therefore, the first task was to determine the calibration coefficient $(\alpha)$ through 
comparison with in situ observations. Then, the waveheight observations were validated against a different in situ instrument operated over a different time period. The spatial and temporal structure of the correlation between all of the radar cell locations and the in situ observations were analyzed, and a method to remove a wind speed-dependent bias in the radar observations was developed.

\section{a. Calibration of radar-observed wave heights}

The individual time series of wave height from each WERA station (1682 cells for CDN, 1836 for NKL) as derived from (1) were compared to the Sontek ADP for a 23-day period in 2005 of YD 78-100. The ADP was chosen as the calibration instrument because it was deployed first and had the longest continuous record. Unfortunately, the maximum value of $H_{s}$ recorded during the calibration was only $1.6 \mathrm{~m}$, thereby limiting the proven range of the wave parameter extraction. Initial comparisons were done without applying a correction factor.

The uncalibrated best linear fits between the CDN and NKL WERA datasets and the near-surface bin of the ADP had slopes of 1.46 and 1.66, respectively, with the radar-derived wave heights being systematically lower than the in situ measurements. The parameter $\alpha$ was then adjusted accordingly to provide the best fit between the WERA derived results and the in situ wave heights.

The linear correlation coefficients between the wave heights from each radar and the buoy were highest within $\pm 45^{\circ}$ of the radar boresight (normal to the receive array; see Figs. 5a,b). The correlations for cells located close to the boresight were higher than for the cells located closest to the ADP, which was located at $55^{\circ}$ to the boresight. Although the angle between the waves and the radar could contribute to the low correlation at large off-boresight angles, the systematic decreasing correlation moving away from the boresight suggests that this is not the dominant mechanism. The lower $r$ values at large angles from the radar boresight are likely due to lower SNR, causing increased sidelobe contributions to the Doppler spectra. The beam forming of a phased-array such as the WERA is weighted to suppress sidelobe returns. Typically they are many decibels below the main lobe signals. However, as the beam is steered away from the boresight, the sidelobe suppression is less effective. For current measurement this is rarely a problem except when there are large radar cross-section inhomogeneities over the illuminated area of the ocean, as observed by Haus et al. (2004). However, the secondorder peaks in the Bragg spectrum, which are used for wave measurements, are more likely to be confused with

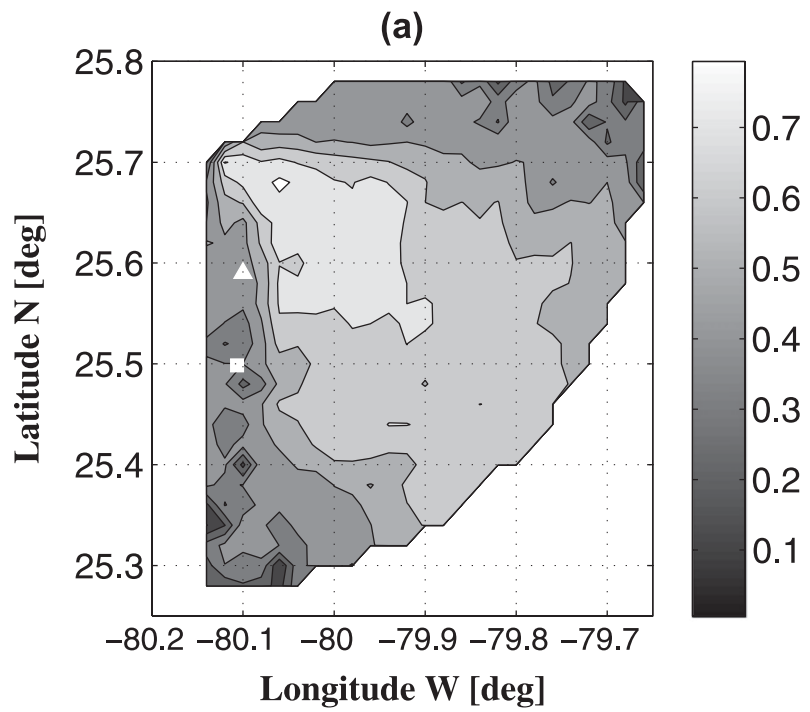

(b)

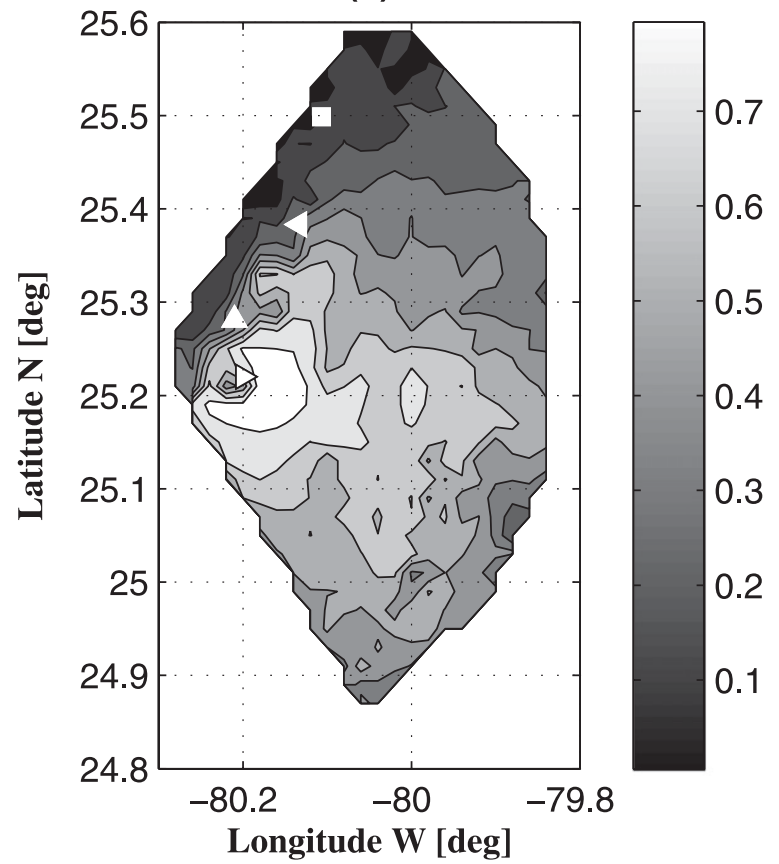

FIG. 5. Linear correlation coefficient for wave height extracted from single-site observations from each individual WERA cell and WADP from YD 79 to 100 2005. Grayscale indicates correlation coefficient. The position of WADP within each radar measurement domain is marked (white $\mathbf{a}$ ). (a) CDN to WADP correlation coefficients. The location of the Fowey Rocks CMAN station is marked (white $\mathbf{\Delta}$ ). (b) NKL to WADP correlation coefficients. The location of Turtle Reef (white $\boldsymbol{\Delta}$ ), Ajax reef (white 4 ), and Carysfort Reef Light (white $\rightarrow$ ) are marked. 
TABLE 2. Linear correlation coefficients for $H_{s}$ between all available platforms obtained during the validation period (YD 100-145). "WERA-CDN" and "WERA-NKL" were obtained using the cell that was best correlated with Sontek during calibration (YD 75-99). "WERA-both" is the average of the two single-site results.

\begin{tabular}{|c|c|c|c|c|c|c|c|c|}
\hline & TAB-N & TAB-S & SNTK & RDI-N & RDI-S & WERA-NKL & WERA-CDN & WERA-Both \\
\hline TAB-N & 1 & & & & & & & \\
\hline TAB-S & 0.97 & 1 & & & & & & \\
\hline SNTK & 0.93 & 0.93 & 1 & & & & & \\
\hline RDI-N & 0.95 & 0.94 & 0.93 & 1 & & & & \\
\hline RDI-S & 0.95 & 0.95 & 0.92 & 0.95 & 1 & & & \\
\hline WERA-NKL & 0.80 & 0.81 & 0.83 & 0.80 & 0.80 & 1 & & \\
\hline WERA-CDN & 0.71 & 0.70 & 0.72 & 0.71 & 0.70 & 0.59 & 1 & \\
\hline WERA-Both & 0.85 & 0.85 & 0.86 & 0.85 & 0.84 & 0.91 & 0.87 & 1 \\
\hline
\end{tabular}

sidelobe returns than the first-order peaks because of the lower SNR.

Limiting the wave observations to smaller off-boresight angles than those used for current observations is required and should provide reasonable results given the pattern of the correlations observed in Fig. 5. In the present study this required selection of locations for wave extraction displaced in an along-shelf direction from the locations of the in situ measurements. To assess whether this spatial displacement introduces significant errors in the wave characteristics, data from the two Triaxys buoy locations (some $7 \mathrm{~km}$ apart in the alongshelf direction and at the same depth) were compared. The wave-height time series from the two buoys were highly correlated ( $r=0.97$, see Table 2$)$, suggesting that the uncertainties introduced by the alongshore separation between the radar observation cell and in situ observations (some $20 \mathrm{~km}$ ) were not significant.

Exceptions to the pattern of high correlation between radar- and ADP-derived wave heights at small angles from the radar boresight were found at areas corresponding to locations of shallow reefs. Over the reef near Carysfort Light (Fig. 5b) the correlation dropped significantly relative to nearby values. This effect was also observed at Fowey Rocks Light (Fig. 5a). The lower correlations over shallow reefs are attributed to significant bathymetric changes (the $\sim 1$-m-deep reef crest and the 9-m-deep location of the ADP) that would alter the wave phase speed and the corresponding wavenumber $(k)$, which is not accounted for in the extraction algorithms. For the purposes of the present study these locations will not be included in the further analysis.

\section{b. Validation of HF radar-observed wave heights}

Wave-height observations from each station were compared to the northern Triaxys buoy (TAB-N) moored 800-m offshore of the bottom-mounted current meters (Fig. 3b). Because this region encompassed the shelf break, the buoy was in 19-m-deep water while the ADP was in $9 \mathrm{~m}$ of water. During the 45-day validation period that extended from YD 100 to 145 2005, the conditions were characterized by persistent light winds and low wave heights, with a maximum hourly $H_{s}$ of $1.35 \mathrm{~m}$ recorded at TAB-N. The HF radar is sensitive to waves in the frequency range from 0.3 to $0.04 \mathrm{~Hz}$. The Triaxys buoys sample a similar frequency range of $0.35-0.05 \mathrm{~Hz}$. Therefore, although both systems may not resolve some of the wind waves in the lightest winds $\left(<5 \mathrm{~m} \mathrm{~s}^{-1}\right)$ it is not expected that this will have a large effect on the comparisons.

For the typically low wave energy and relatively short period (2-5 s) conditions, the difference in depths between the TAB-N and the ADP was not expected to be significant. Through the linear dispersion relationship the phase speed of the longest (5-s period) waves would only change by $5 \%$ between these depths. However, there was a wave-height-dependent difference in the observations from the two platforms, with the slope of the $H_{s}$ regression between TAB-N and the ADP equal to 1.2 .

The correlations during the validation period (Figs. 6a,b) exhibited a similar spatial distribution as that of the calibration dataset. The highest correlations were for cells located close to the radar-look direction, and they decreased at larger angles with the following exceptions. There was a clear azimuthally distributed band of low correlations between the CDN observations and TAB-N. This is likely produced by recurring noise at this range because it is clearly not physical. Lower correlations over shallow reefs are again evident in these wave heights from both radar stations.

\section{c. Wave-height correction factor}

The time series comparison between the best correlated cells from each WERA station revealed generally good agreement (Fig. 7), with linear correlations between NKL and CDN to the TAB-N mooring of 0.80 and 0.71 , respectively (Table 2 ). The validation study showed that there was a substantial improvement $(r=0.85)$ in the 
(a)

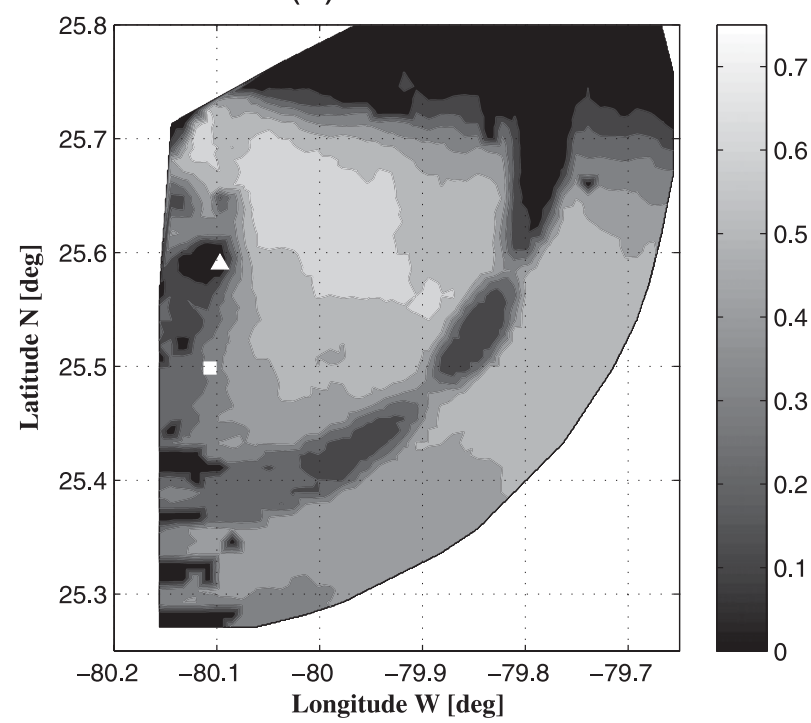

(b)

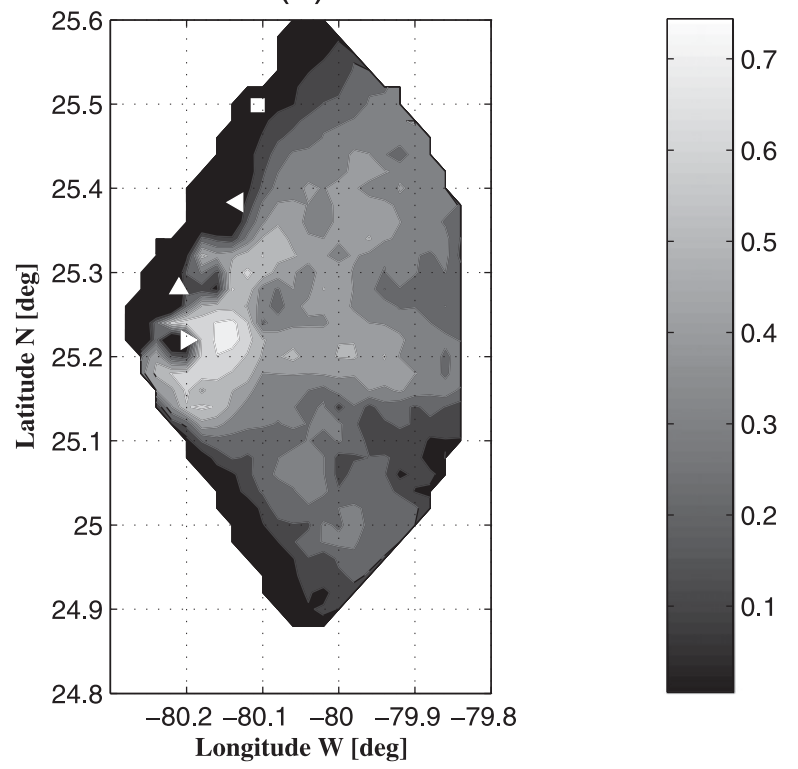

FIG. 6. Linear correlation coefficient for wave height extracted from single-site observations from each individual WERA cell and TAB-N from YD 100-145 2005. Grayscale indicates correlation coefficient. The position of TAB-N within each radar measurement domain is marked (white $\mathbf{m}$ ). (a) CDN to TAB-N correlations. The location of the Fowey Rocks CMAN station is marked (white $\boldsymbol{\Delta}$ ). (b) NKL to TAB-N correlations. The location of Turtle Reef (white $\mathbf{\Delta}$ ), Ajax reef (white 4 ), and Carysfort Reef Light (white are marked.

correlation between the radar and buoy observations when the height estimates from the two sites were averaged (Fig. 8b). This suggests that there is a directional dependence of the wave-height retrievals as discussed by Wyatt (2002). While the Wyatt (2002) directional differences were not large for this range of wave heights, the present data were collected in a different type of wave climate resulting from fetch limitations, topography, and strong surface currents. Correcting for the difference between the calibration and validation instruments, as discussed above, resulted in a slightly better agreement between the radar wave heights and the TAB-N (Fig. 8b).

There was a distinct trend toward increasing differences between the radar- and ADP-observed wave heights as the wind speed increased over the range of $5 \leq$ $U_{10 N} \leq 15 \mathrm{~m} \mathrm{~s}^{-1}$ (Fig. 9a), which was particularly evident in the case of onshore winds exceeding $7 \mathrm{~m} \mathrm{~s}^{-1}$. Depending upon location and season, this wind speed range can encompass a majority of wind speed conditions. For example, in 2005 at the Fowey Rocks Coastal-Marine Automated Network (C-MAN) station (FWYF1), 71\% of the hourly wind speed magnitudes were between 5 and $15 \mathrm{~m} \mathrm{~s}^{-1}$.

To explore this further, the observed wind speed at FWYF1 was used to estimate the local peak wavenumber through (6). When converted to peak period using linear dispersion, these estimates qualitatively agreed with the TAB-N observations, but exhibited a larger range of variability (Fig. $7 b$ ). The peak wavenumbers were then used in the ASF (5) to calculate $\varepsilon_{H}$ using (7). This successfully removed the first-order effects of wind speed on the directional spreading (Fig. 9b). There was no remaining wind speed dependence of the observed wave-height differences, although there was considerable scatter. Closer examination of the distribution of the remaining wave-height differences revealed that there was a relationship with the wind direction relative to the radar boresight. For winds nearly orthogonal to the boresight direction, the radar-derived wave heights are distributed both higher and lower than the in situ observations; while for wind directions within $30^{\circ}$ of the radar boresight, the radar-derived wave heights are biased toward higher values (Fig. 9b). Because the correction factor is proportional to the ratio of the energy at Bragg waves to the energy within the spectral peak (7), this overcorrection for waves moving in the radar-look direction implies that either less energy is being observed at the Bragg wavenumber than the ASF suggests or that there is more energy in the peak waves.

\section{Discussion}

There are three plausible physical mechanisms that can explain the positive bias in the differences between the ASF-derived wave heights and the in situ observations. The first is that the directional distribution of the shorter $\left(k>k_{p}\right)$ waves is no longer unimodal because of the nonlinear wave-wave interactions and/or differential wave breaking. In contrast to the unimodal wave 
(a)

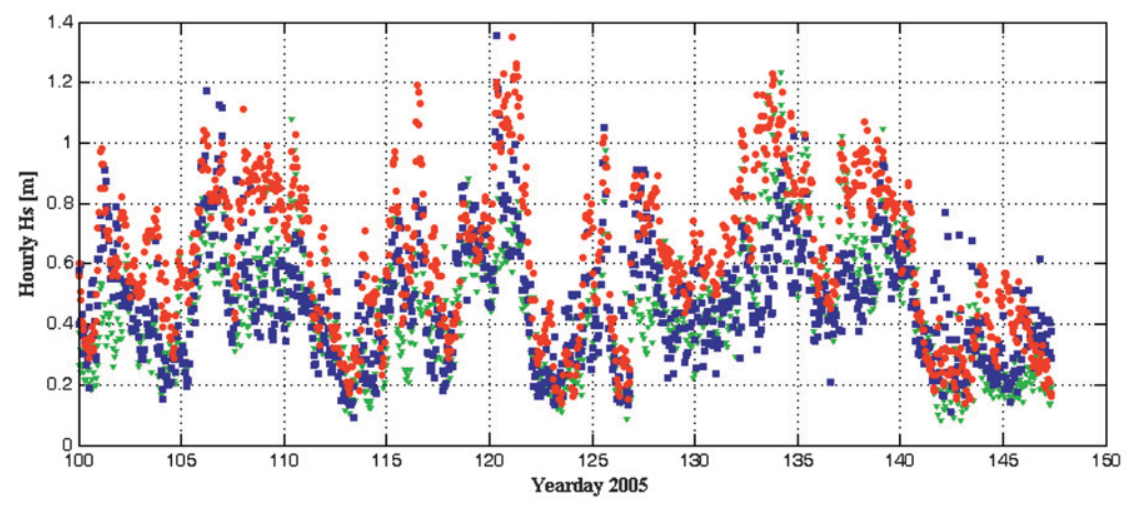

(b)

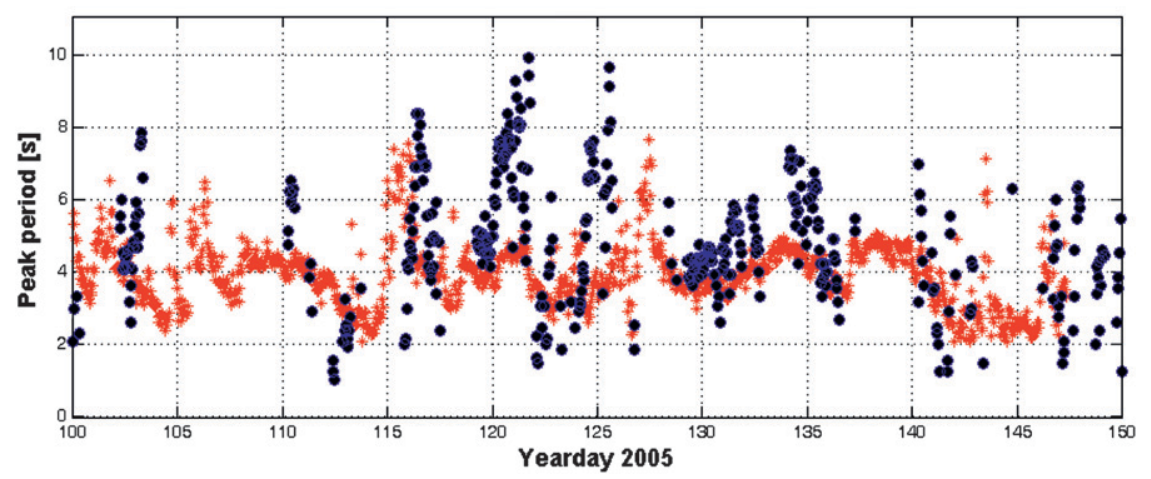

FIG. 7. (a) Time series of hourly wave heights ( $\mathrm{m}$ ) observed at best-correlated WERA cell for each radar station and the northern TriAxys buoy (TAB-N) from YD 100 to 145 2005. TAB-N wave height ( red $\bullet$ ), WERA observations from NKL (green $\boldsymbol{\Delta}$ ), and WERA observations from CDN ( $\mathbf{})$ are shown. (b) TAB-N peak period (*) and period estimates are derived from Fowey Rocks CMAN winds using Eq. (6), and wavenumbers are converted to periods $(\bullet)$ using linear dispersion for onshore wind cases only.

directional energy distributions discussed so far, there is a considerable body of evidence from both models (Banner and Young 1994) and experiments (Ewans 1998; Hwang et al. 2000; Wang and Hwang 2001; Hisaki 2004) that growing wind seas may have bimodal distributions of wave energy about the mean wind-wave direction. The bimodal structure was observed to be most important for those wavenumbers well above $\left(k>3 k_{p}\right)$, the spectral peak by Hwang and Wang (2001). The distinguishing feature of the bimodal directional distribution models (e.g., Ewans 1998; Banner and Young 1994) is that the energy at high wavenumbers in the wind direction is lower than that at off-wind angles.

This prediction is consistent with the observed overcorrection of the wave heights for the small wind-wave angles observed here (Fig. 9a), resulting from lower energy at the Bragg wavenumbers than those specified by the unimodal ASF. A bimodal Bragg wave field would, however, also suggest that there should be more energy at
Bragg wavenumbers at large angles to the wind direction, leading to undercorrection at large angles to the wind. This was not observed in our results (Fig. 9b); however, it is possible that weaker SNR might obscure the effect at large off-wind angles by adding large variance to the observations. The effect would also be expected to be more evident at larger wind velocities as the Braggwavenumber-to-peak-wavenumber ratio increases; such a trend was not observed here.

The second potential mechanism is the refraction of the wave field by strong surface current shears, which would result in a different response at the Bragg wavenumber than at the peak energy-containing wavenumbers. Because these observations were conducted in the Florida Straits, they included the high velocity (reaching $\sim 2 \mathrm{~m} \mathrm{~s}^{-1}$ ) and vorticity ( $>2 f$, where $f$ is the local Coriolis parameter) of the Florida Current. Previous studies of fetch-limited wave growth (Haus 2007) and surface stress (Drennan and Shay 2006) have shown that refraction of 
(a)

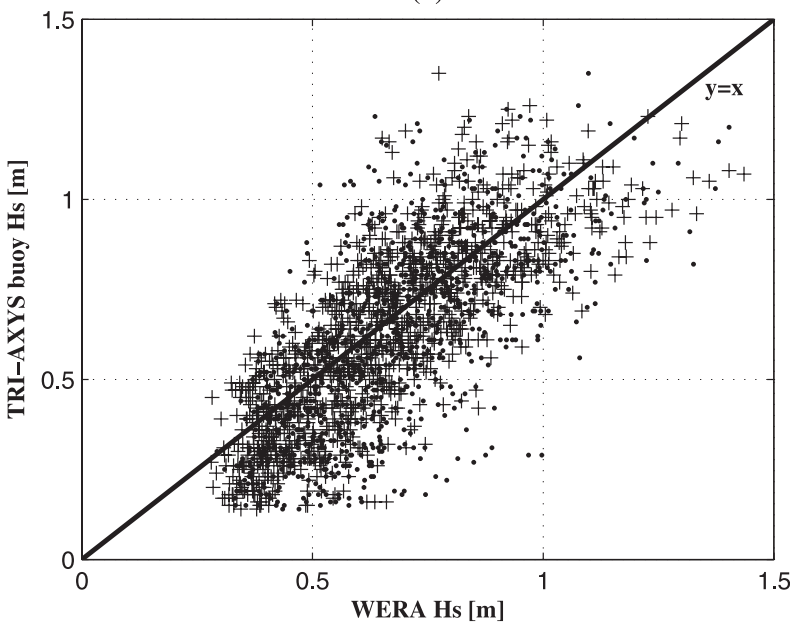

(b)

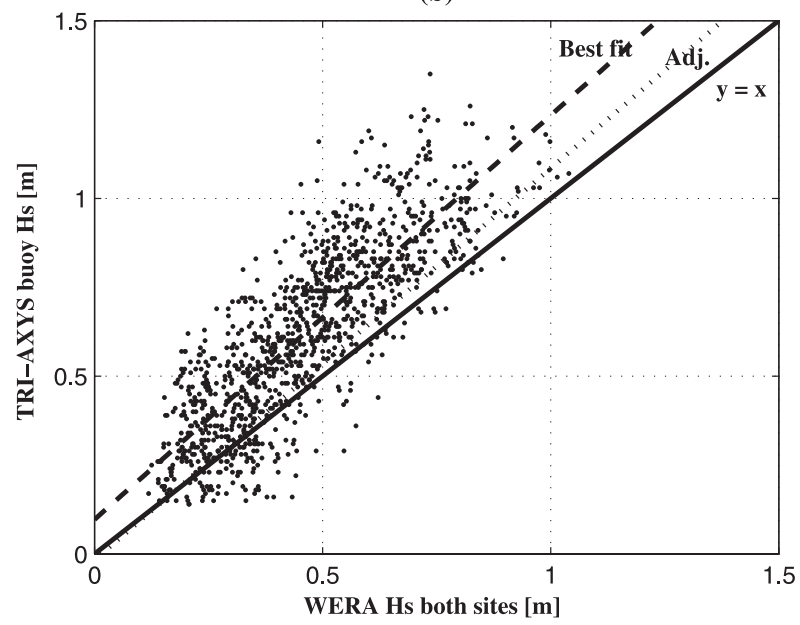

FIG. 8. WERA $H_{s}$ vs TAB-N $H_{s}$ for validation time period (YD 100-145). (a) Scatter diagrams of WERA best-correlated cell from both sites vs TAB-N ( + : Crandon, a: NKL), $y=x$ line is shown. (b) Average of both sites vs TAB-N, best linear fit line (--), $y=x(-)$ and adjusted best fit ( $\mathbf{m})$ to account for SNTK TAB-N regression from calibration period (Table 2).

the wave field away from the wind direction by high surface current vorticity is an important effect in this region.

An important consideration for HF radar studies is that although the decimeter-scale Bragg scattering waves are not typically strongly modulated by long waves, the scale separation between $k_{B}$ and $k_{p}$ can become large and potentially important for the consideration of both wave refraction and breaking at moderate to high wind speeds (Fig. 2). This has received little attention in the HF radar literature because the basic scattering theory of Barrick (1977a) does not consider these effects. In contrast, there has been a considerable effort to determine the effect of long waves and surface (a)

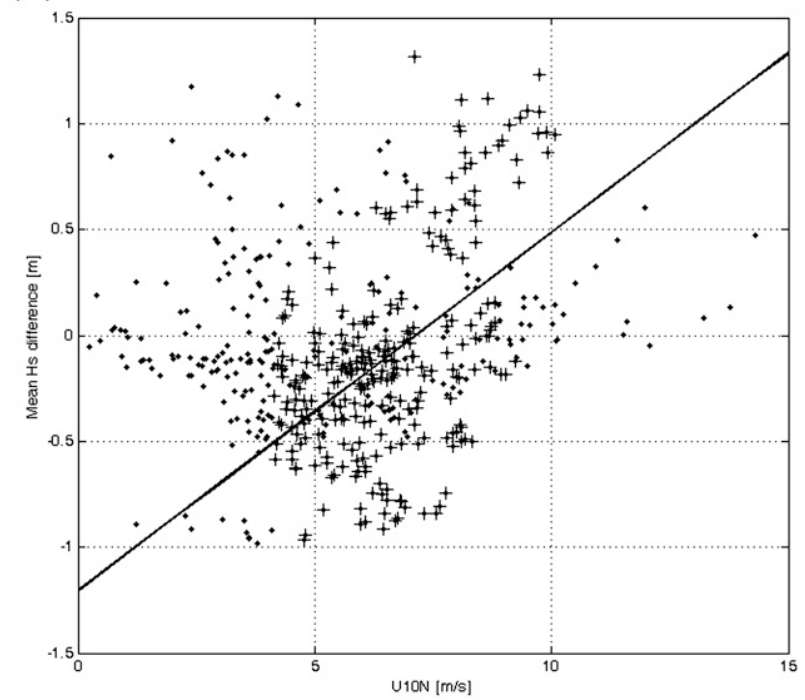

(b)

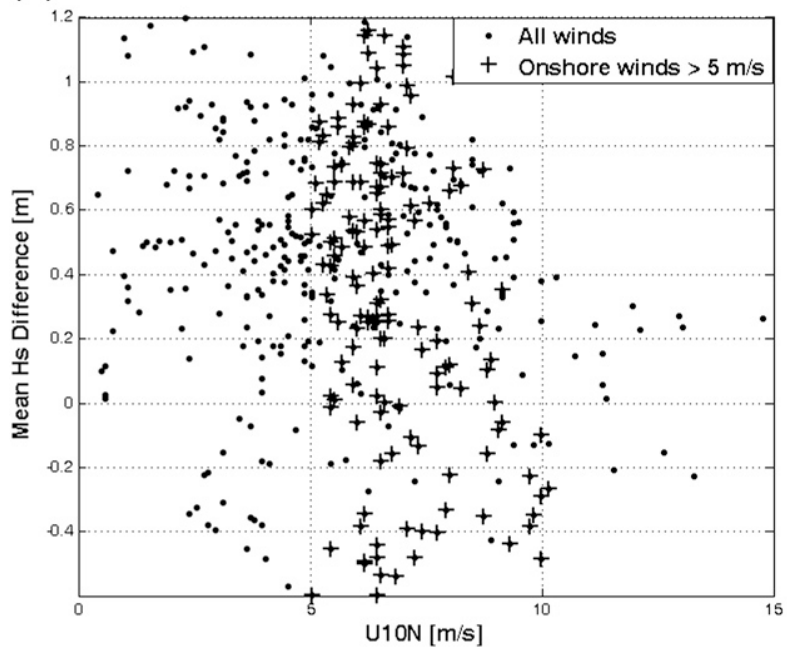

FIG. 9. Wind speed dependence of mean difference between WERA $H_{s}$ for all cells from Crandon HF station and in situ $H_{s}(\mathrm{~m})$ observed at WADP in Fig. 3 (CDN-WADP). (a) After calibration for best fit for the period from YD 78-99; - for all times, + for times when the wind direction at the Fowey Rocks CMAN is onshore and greater than $5 \mathrm{~m} \mathrm{~s}^{-1}$. Least squares best-fit line for all onshore wind cases (line). (b) Difference (.) between the corrected WERA $H_{s}$ and the W-ADP $H_{s}$ (corrected CDNWADP) based on ASF related to FWYF1 wind speed. Cases when FWYF1 wind was within $30^{\circ}$ of the radar-look direction $(+)$. Cases when FWYF1 direction was within $30^{\circ}$ of orthogonal to the radar-look direction $(\boldsymbol{\square})$.

currents on the centimeter-scale waves responsible for microwave Bragg scattering.

Kudryavtsev et al. (2005), in an extension of earlier work by Kudryavtsev et al. (2003), presented a model of the scattering of microwave radar signals that relied upon the concept of the relaxation time of the surface 
waves. In their model the peak energy-containing waves are shifted by current gradients, but short equilibrium range waves respond to the local wind conditions. Zhang et al. (2009) showed through a combination of in situ wave observations and HF radar surface current measurements that the shortest waves were in the wind direction. These short waves did not respond to a sheared current field by refracting in the same manner as the peak waves, confirming the importance of the relaxation scale. The current shears then cannot explain the overcorrection for wave height at small angles (Fig. 9b), and in fact they would mitigate this by causing more peak wave energy to propagate in the off-wind direction (Haus 2007).

A third mechanism that could result in a differing directional distribution of the peak energy-containing waves is the slanting fetch effect first suggested by Donelan et al. (1985). Pettersson (2004) observed this effect in an enclosed bay and Ardhuin et al. (2007) incorporated it in a model of fetch-limited wave growth and found improved results. This mechanism will only be important if there are significant differences between the effective fetch and the offshore distance for particular wind directions. In the present measurement domain (Fig. 3) this could occur in either onshore or offshore directed winds. The shifting of the peak waves away from the wind direction would have a similar effect as the sheared currents, and also would not contribute to the overcorrection at small off-wind angles.

None of the identified mechanisms are clearly supported by the results of this study, although the limited range of wave heights observed does not provide sufficient confidence to make firm conclusions. To quantify the structure of the directional distribution of the Bragg waves and to determine the influence of surface current vorticity and the slanting fetch effect, it will be necessary to collect much longer records over a much wider range of wave conditions than is available here. Expanded parameter ranges might then allow an appropriate correction factor to be defined that can incorporate both wind speed and the relative direction. In such a case the remaining challenge to routinely determine and apply the appropriate correction factor will be to define the relative wave-to-radar-look direction $\left(\theta^{r w}\right)$.

The difficulty in determining $\theta^{r w}$ was recognized by Maresca and Georges (1980), who estimated the sensitivity of sky wave HF wave-height retrievals to inaccuracies in $\theta^{r w}$ to be as large as $25 \%$. There are three basic approaches available to determine $\theta^{r w}$. The first of these is to assume homogeneity of the wave field over a large enough area to use different look directions from the same narrowbeam radar (Heron and Rose 1986). Similarly, broad-beam observations (Lipa and Nyden
2005) average over large azimuths and thereby are not sensitive to $\theta^{r w}$. The second method is to use independent wind information to provide $\theta^{r w}$, assuming that the wind and waves are aligned. The third approach is to use the information contained in the ratio of the first-order peaks of the Doppler spectrum (Fig. 1) to determine $\theta^{r w}$ (Wyatt et al. 1997). This enables observations in cases where the short-wave direction is different from the wind direction because of currents (Drennan and Shay 2006; Haus 2007; Hisaki 2002; Zhang et al. 2009), topography, or slanting fetch limitations (Donelan et al. 1985; Ardhuin et al. 2007).

\section{Summary}

The use of the scaled ratio of second- to first-order backscattering to determine the significant wave height can provide useful information from a single radar station with some limitations. In particular, the high-resolution observations must be limited in the case of phased arrays to angles within $45^{\circ}$ of the radar boresight. Use of a wind speed-dependent formulation for the directional spreading function can provide useful information, but significant differences between radar and in situ observations remain.

The wind speed dependence of the wave-height retrieval was eliminated through the use of a correction factor based on the Apel (1994) directional spectrum for both the Bragg waves and the peak energy-containing waves. However, significant differences remain that in some cases are related to the angle between the wind and the radar-look direction. When the wind was aligned with the radar boresight, the corrected HF radar wave observations were biased high. Varying relative directional distributions between the HF Bragg scattering waves and the peak energy-containing waves were the likely cause of the observed difference. Alternative mechanisms leading to these differences were discussed but could not be distinguished between given the limited wave-height range of the observations available.

Acknowledgments. We thank the following people who have helped us with locations for the radars: Dr. Renate Skinner, Mr. Jim Duquesnel, and Mr. Eric Kiefer from Florida DEP for our site in North Key Largo Botanical Reserve; and Mr. Kevin Kirwan and Mr. Ernest Lynk from Miami-Dade County Parks and Recreation for our site in Crandon Park on Key Biscayne. Thomas Cook was critical to this research through his work with the WERA measurement group at the University of Miami. Jerome Fiechter and Mike Rebozo assisted with the field measurements. Richard Curry of Biscayne National Park assisted with the current meter 
deployments. This work was supported by the United States Office of Naval Research through the SEACOOS program.

\section{REFERENCES}

Apel, J. R., 1994: An improved model of the ocean surface wave vector spectrum and its effects on radar backscatter. J. Geophys. Res., 99, 16 269-16 291.

Ardhuin, F., T. H. C. Herbers, G. P. van Vledder, K. P. Watts, R. Jensen, and H. C. Graber, 2007: Swell and slanting-fetch effects on wind wave growth. J. Phys. Oceanogr., 37, 908-930.

Banner, M. L., 1990: Equilibrium spectra of wind waves. J. Phys. Oceanogr., 20, 966-984.

— , and I. R. Young, 1994: Modeling spectral dissipation in the evolution of wind waves. Part I: Assessment of existing model performance. J. Phys. Oceanogr., 24, 1550-1571.

Barrick, D. E., 1972: Remote sensing of sea state by radar. Remote Sensing of the Troposphere, V. E. Derr, Ed., U.S. Government Printing Office, 12.1-12.6.

_ 1977a: Extraction of wave parameters from measured HF radar sea-echo Doppler spectra. Radio Sci., 12, 415-424.

- 1977b: The ocean wave height nondirectional spectrum from inversion of HF sea-echo Doppler spectrum. Remote Sens. Environ., 6, 201-227.

Crombie, D. D., 1955: Doppler spectrum of sea echo at $13.56 \mathrm{Mc} . \mathrm{s}^{-1}$. Nature, 175, 681-682.

de Valk, C., A. Reniers, J. Atanga, A. Vizinho, and J. Vogelzang, 1999: Monitoring surface waves in coastal waters by integrating HF radar measurement and modeling. J. Coastal Eng., 37, 431-453.

Donelan, M. A., and W. J. Pierson Jr., 1987: Radar scattering and equillibrium ranges in wind-generated waves with application to scatterometry. J. Geophys. Res., 92, 4971-5029.

_ - J. Hamilton, and W. H. Hui, 1985: Directional spectra of wind generated waves. Philos. Trans. Roy. Soc. London, 315A, 509-562.

Drennan, W. M., and L. K. Shay, 2006: On the variability of the fluxes of momentum and sensible heat. Bound.-Layer Meteor., 119, 81-107.

Ewans, K. C., 1998: Observations of the directional spectrum of fetch-limited waves. J. Phys. Oceanogr., 28, 495-512.

Graber, H. C., and M. L. Heron, 1997: Wave height measurements from $\mathrm{HF}$ radar. Oceanography, 10, 90-92.

—, E. A. Terray, M. A. Donelan, W. M. Drennan, J. C. Van Leer, and D. B. Peters, 2000: ASIS-A new air-sea interaction spar buoy: Design and performance at sea. J. Atmos. Oceanic Technol., 17, 708-720.

Gürgel, K.-W., G. Antonischki, H.-H. Essen, and T. Schlick, 1999: Wellen Radar (WERA): A new ground-wave HF radar for ocean remote sensing. Coastal Eng., 37, 219-234.

_- H.-H. Essen, and T. Schlick, 2006: An empirical method to derive ocean waves from second-order Bragg scattering: Prospects and limitations. IEEE J. Oceanic Eng., 31, 804-811.

Hasselmann, D. E., M. Kunckel, and J. A. Ewing, 1980: Directiona wave spectra observed during JONSWAP 1973. J. Phys. Oceanogr., 10, 1264-1280.

Hasselmann, K., 1971: Determination of ocean wave spectra from Doppler radio return from the sea surface. Nature, 229, 16-17.

Haus, B. K., 2007: Surface current effects on the fetch limited growth of wave energy. J. Geophys. Res., 112, C03003, doi:10.1029/2006JC003924.
J. D. Wang, J. Martinez-Pedraja, and N. Smith, 2004: Southeast Florida Shelf circulation and volume exchange, observations of km-scale variability. Estuarine Coastal Shelf Sci., 59, 277-294.

—, R. Ramos, H. C. Graber, L. K. Shay, and Z. R. Hallock, 2006: Remote observation of the spatial variability of surface waves interacting with an estuarine outflow. IEEE J. Oceanic Eng., 31, 835-849.

Heron, M. L., and R. J. Rose, 1986: On the application of HF ocean radar to the observation of temporal and spatial changes in wind direction. IEEE J. Oceanic Eng., 11, 210-218.

, P. E. Dexter, and B. T. McGann, 1985: Parameters of the airsea interface by high-frequency ground-wave Doppler radar. Aust. J. Mar. Freshwater Res., 36, 655-670.

Heron, S. F., and M. L. Heron, 1998: A comparison of algorithms for extracting significant wave height from HF radar ocean backscatter spectra. J. Atmos. Oceanic Technol., 15, 1157-1163.

Hisaki, Y., 1996: Nonlinear inversion of the integral equation to estimate ocean wave spectra from HF radar. Radio Sci., 31, $25-39$.

_ 2002: Short-wave directional properties in the vicinity of atmospheric and oceanic fronts. J. Geophys. Res., 107, 3188, doi:10.1029/2001JC000912.

, 2004: Short-wave directional distribution for first-order Bragg echoes of the HF ocean radars. J. Atmos. Oceanic Technol., 21, 105-121.

- 2005: Ocean wave directional spectra estimation from an HF ocean radar with a single antenna array: Observation. J. Geophys. Res., 110, C11004, doi:10.1029/2005JC002881.

Howell, R., and J. Walsh, 1993: Measurement of ocean wave spectra using narrow-beam HF radar. J. Oceanic Eng., 18, 296-305.

Hwang, P. A., and D. W. Wang, 2001: Directional distributions and mean square slopes in the equilibrium and saturation ranges of the wave spectrum. J. Phys. Oceanogr., 31, 1346-1360.

,-- , E. J. Walsh, W. B. Krabill, and R. N. Swift, 2000: Airborne measurements of the wavenumber spectra of ocean surface waves. Part II: Directional distribution. J. Phys. Oceanogr., 30, 2768-2787.

Kudryavtsev, V., D. Hauser, G. Caudal, and B. Chapron, 2003: A semiempirical model of the normalized radar cross-section of the sea surface 1. Background model. J. Geophys. Res., 108, 8054, doi:10.1029/2001JC001003.

— D. Akimov, J. Johannessen, and B. Chapron, 2005: On radar imaging of current features: 1. Model and comparison with observation. J. Geophys. Res., 110, C07016, doi:10.1029/ 2004JC002505.

Lipa, B., 1978: Inversion of second-order radar echoes from the sea. J. Geophys. Res., 83, 959-962.

— radar sea echo: Mathematical theory and modeling. Radio Sci., 21, 81-100.

- and B. Nyden, 2005: Directional wave information from the SeaSonde. IEEE J. Oceanic Eng., 30, 221-231.

Long, A. E., and D. B. Trizna, 1973: Mapping of North Atlantic winds by $\mathrm{HF}$ radar sea backscatter interpretation. IEEE Trans. Antennas Propag., 21, 680-685.

Longuet-Higgins, M. S., D. E. Cartwright, and N. D. Smith, 1963: Observations of the directional spectrum of sea waves using the motions of a floating buoy. Ocean Wave Spectra, PrenticeHall, 111-136.

Maresca, J. W., and T. M. Georges, 1980: Measuring rms wave height and the scalar ocean wave spectrum with HF skywave radar. J. Geophys. Res., 85, 2759-2771. 
Mitsuyasu, A., F. Tasai, T. Suhara, S. Mizuno, M. Ohkusu, T. Honda, and K. Rikiishi, 1975: Observations of the directional spectrum of ocean waves using a cloverleaf buoy. J. Phys. Oceanogr., 5, 750-760.

Parks, A. B., L. K. Shay, W. E. Johns, J. Martinez-Pedraja, and K.-W. Gurgel, 2009: HF radar observations of small-scale surface current variability in the Straits of Florida. J. Geophys. Res., 114, C08002, doi:10.1029/2008JC005025.

Pettersson, H., 2004: Wave growth in a narrow bay. Ph.D. dissertation, University of Helsinki, 33 pp.

Ramos, R. J., H. C. Graber, and B. K. Haus, 2009: Observation of wave energy evolution in coastal areas using HF radar. J. Atmos. Oceanic Technol., 26, 1891-1909.

Shay, L. K., J. Martinez-Pedraja, T. M. Cook, B. K. Haus, and R. Weisberg, 2007: High-frequency radar mapping of surface currents using WERA. J. Atmos. Oceanic Technol., 24, 484-503.

Voulgaris, G., B. K. Haus, P. A. Work, L. K. Shay, H. Seim, R. H. Weisberg, and J. R. Nelson, 2008: Waves initiative within SEACOOS. Mar. Technol. Soc. J., 42, 68-80.

Wang, D. W., and P. A. Hwang, 2001: Evolution of the bimodal directional distribution of ocean waves. J. Phys. Oceanogr., 31, $1200-1221$.
Work, P. A., 2008: Nearshore directional wave measurements by surface-following buoy and acoustic Doppler current profiler. Ocean Eng., 35, 727-737.

Wyatt, L. R., 1990: A relaxation method for integral inversion applied to HF radar measurement of the ocean wave directional spectrum. Int. J. Remote Sens., 11, 1481-1494.

— , 2002: An evaluation of wave parameters measured using a single HF radar system. Can. J. Remote Sens., 28, 205-218.

— L L. J. Ledgard, and C. W. Anderson, 1997: Maximum-likelihood estimation of the directional distribution of $0.53-\mathrm{Hz}$ ocean waves. J. Atmos. Oceanic Technol., 14, 591-603.

_ - S. P. Thompson, and R. R. Burton, 1999: Evaluation of high frequency radar wave measurement. Coastal Eng., 37, 259-282. , G. Liakhovetski, H. Graber, and B. K. Haus, 2005: Factors affecting the accuracy of SHOWEX HF radar wave measurements. J. Atmos. Oceanic Technol., 22, 847-859.

_ J. J. Green, and A. Middleditch, 2009: Signal sampling impacts on HF radar wave measurement. J. Atmos. Oceanic Technol., 26, 793-805.

Zhang, F. W., W. M. Drennan, B. K. Haus, and H. C. Graber, 2009: On wind-wave-current interaction during the Shoaling Waves Experiment. J. Geophys. Res., 114, C01018, doi:10.1029/ 2008JC004998. 